\title{
EL PROCESO MONITORIO. TENDENCIA DEL DERECHO PROCESAL IBEROAMERICANO*
}

\author{
Magda Isabel Quintero Pérez** \\ Samir Alberto Bonett Ortiz"w* \\ Asesor: Carlos Alberto Colmenares Uribe ${ }^{* * * * *}$
}

\section{RESUMEN}

El proceso monitorio es una tendencia del derecho procesal iberoamericano, así lo demuestran el Código Procesal Civil Modelo para Iberoamérica y sus Propuestas para las Bases del Nuevo Código, y los casos de Uruguay, Venezuela, Brasil, Argentina (Provincia de La Pampa), España, Perú, Chile, Honduras, Costa Rica, El Salvador y

Fecha Recibido: abril 11 de 2014 • Fecha Aceptado: julio 31 de 2014

* La base de este artículo fue presentada como ponencia en el Concurso para Abogados en el marco de las XXIV Jornadas Iberoamericanas de Derecho Procesal, organizadas por el Instituto Iberoamericano de Derecho Procesal y el Instituto Colombo Panameño de Derecho Procesal, en Ciudad de Panamá, el 26, 27 y 28 de marzo de 2014

** Abogada. Egresada y Especialista en Derecho Público de la Universidad Libre Seccional Cúcuta. Candidata a Magister en Derecho con Énfasis en Responsabilidad Contractual y Extracontractual Civil y del Estado. Directora Ejecutiva del Instituto Colombiano de Derecho Procesal. Docente de la Universidad Libre de Colombia. Miembro de los Institutos Colombiano e Iberoamericano de Derecho Procesal. Mail: magdaisabelqp@hotmail.com

*:** Abogado. Egresado y Especialista en Derecho Laboral de la Universidad Libre Seccional Cúcuta. Secretario del Instituto Colombiano de Derecho Procesal, Capítulo Norte de Santander. Docente Investigador y Codirector de los Semilleros de Derecho Procesal y Derecho del Trabajo y de la Seguridad Social de la Universidad Libre Seccional Cúcuta. Miembro de los Institutos Colombiano e Iberoamericano de Derecho Procesal. Abogado asesor y litigante. Mail: samir.bonett@unilibrecucuta.edu.co

***** Profesor de la Universidad Libre Seccional Cúcuta, Colombia. Miembro de los Institutos Colombiano e Iberoamericano de Derecho Procesal. 
Colombia, pero como toda idea nueva puede ser objeto de resistencia y crítica porque nuestra tradición procesal nos ha enseñado que el título ejecutivo judicial se obtiene con la sentencia y que a ella se llega después de una serie sucesiva de actos (litis contestatio, pruebas, alegatos y sentencia) y precisamente el proceso monitorio altera ese orden casi prescindiendo formalmente de las etapas probatoria y de alegatos para iniciar casi con la sentencia. Como con toda idea nueva, antes de la resistencia y crítica, es necesario conocer sus fundamentos, como su fin, naturaleza y la experiencia de otros países, para tener una idea más aproximada y luego juzgar su conveniencia o no. Y ese es el objetivo de este estudio: tratar de exponer los principales fundamentos del proceso monitorio y hacer un repaso por los países de Iberoamérica que lo han implementado, y así saber si conviene o no.

Palabras clave: proceso monitorio, procedimiento ordinario, inversión del contradictorio, tutela judicial efectiva, derecho procesal iberoamericano.

\section{Abstract:}

The payment procedure is a trend of Latin American procedural law, as demonstrated by the Civil Procedure Code Model for Latin America and the Tender Proposals for New Code, and cases of Uruguay, Venezuela, Brazil, Argentina (Province of La Pampa), Spain, Peru, Chile, Honduras, Costa Rica, El Salvador and Colombia, but like any new idea can be resistance and criticism because our judicial tradition has taught us that the judicial enforcement is obtained with the sentence and that she will get after a succession of acts (litis contestatio, evidence, arguments and judgment) and the payment procedure alters, precisely, that order formally almost regardless of the evidence and pleadings stage to start almost to the decision. As with any new idea, before the resistance and criticism, it is necessary to know its foundations, as its purpose, nature and the experience of other countries, to have a better idea and then, judge their convenience or not. And that is the goal of this study: to try to outline the main foundations of the payment procedure and do a review of the Latin American countries that have implemented it, and thus know whether or not to.

Key words:: Payment procedure, standard procedure, contradictory investment, effective remedy, Latin American procedural law. 


\section{INTRODUCCIÓN}

La idea principal de este artículo es resaltar el proceso monitorio como una de las tendencias más importantes y beneficiosas del derecho procesal iberoamericano, iniciando por sus nociones generales (definición, fin, naturaleza, clasificación y relación con el debido proceso), y haciendo énfasis en un repaso por los países iberoamericanos que lo han implementado, lo que muestra su amplitud y beneficio, pero sin pretender hacer un estudio amplio, lo que es imposible por los límites del artículo y porque ya grandes procesalistas han hecho estudios fundamentales, como Piero Calamandrei ${ }^{1}$, entre muchos, y recientemente, Jordi Nieva Fenoll, Juan Pablo Correa Delcasso, Rodrigo Rivera Morales y Carlos Alberto Colmenares Uribe, entre muchos².

Este estudio se divide en tres partes: en la primera, se tratarán las nociones generales del proceso monitorio (definición, fin, naturaleza, clasificación y relación con el debido proceso); en la segunda, el proceso monitorio en Iberoamérica; y en la tercera, el proceso monitorio como tendencia del derecho procesal iberoamericano.

\section{NOCIONES GENERALES}

\subsection{Definición}

El monitorio, al margen de la controversia que pueda existir si es proceso, procedimiento o estructura ${ }^{3}$, en un sentido amplio, es un mecanismo procesal que sirve para la creación de un título ejecutivo y para garantizar la tutela judicial efectiva de otras pretensiones, sin necesidad de tramitar todas las etapas del clásico procedimiento ordinario para obtener la sentencia que declare el derecho en controversia, con una justificación como casi ningún tipo de proceso tiene, pues como dice el maestro Jairo Parra Quijano ${ }^{4}$, citando las palabras de Vittorio Denti: "Redescubrimiento de los vínculos entre derecho material y proceso, para el futuro de la ciencia procesal”.

1 CAlamandreI, Piero. El Procedimiento Monitorio. Buenos Aires: Librería El Foro, 2006. Para mayor doctrina, léase a NIEVA FENOLL, Jordi. Aproximación al Origen del Procedimiento Monitorio. En: El Procedimiento Monitorio en América Latina. Pasado, Presente y Futuro. Bogotá DC: Editorial Temis SA, 2013. pp. 1-16.

2 NIEVA FENOLL, Jordi et al. El Procedimiento Monitorio en América Latina. Pasado, Presente y Futuro. Op. cit.

3 COlmenares URIBE, Carlos Alberto. El Procedimiento Monitorio en América Latina. Pasado, Presente y Futuro. Op. cit., pp. 110-120.

4 PARRA QUIJANO, Jairo. Prólogo a El Procedimiento Monitorio en América Latina. Pasado, Presente y Futuro. Op. cit., p. VII. 
El proceso monitorio surge como algo distinto del clásico procedimiento ordinario (una especie del proceso de conocimiento), que sirve para lograr una declaración de un derecho, generalmente con esta técnica por etapas: 1) litis contestatio (demanda y oportunidad de defensa), 2) práctica de pruebas, 3) alegatos de conclusión, y 4) sentencia. El monitorio nació como una forma diferente para obtener el título ejecutivo: quien pretende cierto derecho ya no debe someterse a todas las etapas del clásico procedimiento ordinario, sino que este proceso inicia dándole la razón, siempre que el demandado la "ratifique" mediante el pago, aunque si guarda silencio se dictará sentencia que será la base para iniciar la ejecución, pero sin desconocer su derecho de defensa, dándole la oportunidad de oponerse a la pretensión, con lo cual el proceso monitorio termina e inicia el proceso de conocimiento (procedimiento ordinario o verbal, según cada país).

\subsection{Fin}

El fin del proceso monitorio puede ser en sentido amplio servir para la creación de un título ejecutivo y para garantizar la tutela judicial efectiva de otras pretensiones. Esto depende de cada país como lo regule. Por ejemplo, la más reciente adopción del proceso monitorio ocurrió en Colombia con el Código General del Proceso (ley 1564 del 12 de julio de 2012, arts. 419 a 421), que limitó su procedencia a la pretensión de “... pago de una obligación en dinero, de naturaleza contractual, determinada y exigible que sea de mínima cuantía...", mientras que en otros países, como Uruguay, el Código General del Proceso (Ley 15.982 del 6 de octubre de 1988) establece la procedencia del proceso monitorio para el ejecutivo y estos otros casos: 1) entrega de la cosa (art. 364), 2) entrega efectiva de la herencia (art. 365), 3) pacto comisorio (art. 366), 4) escriturización forzada (art. 367), 5) resolución de contrato de promesa (art. 368), 6) separación de cuerpos y divorcio (art. 369), y 7) cesación de condominio de origen contractual (art. 370). El Código Procesal Civil Modelo para Iberoamérica de 1988 adoptado por el Instituto Iberoamericano de Derecho Procesal estableció el proceso monitorio para varios casos, así: "El proceso de estructura monitoria se aplicará en los casos especialmente previstos por la ley y además en los siguientes procesos: 1) ejecutivos; 2) desahucio o desalojos; 3) entrega de la cosa; 4) entrega efectiva de la herencia; 5) resolución por falta de pago o escrituración judicial de promesas inscriptas en los respectivos registros (compra-venta de inmueble o de establecimiento o de empresa comercial o de unidad en propiedad horizontal)" (art. 311), como lo advierte Carlos Alberto Colmenares Uribe ${ }^{5}$.

COLMENARES URIBE, Carlos Alberto. Estructura Monitoria y la Hipoteca. En: Memorias XXXI Congreso Colombiano de Derecho Procesal. Cartagena de Indias, 2010. p. 1068. 
1.2.1 Jurisprudencia española: Jorge Garberí Llobregat ${ }^{6}$ cita esta jurisprudencia7: "El monitorio es un proceso carente de fase declarativa, y su finalidad radica en obtener un título, que permita abrir el procedimiento de ejecución forzosa" (subrayado fuera de texto). En España el fin es exclusivamente la creación de un título ejecutivo, como en Colombia, y contrario a Uruguay.

\subsection{Naturaleza}

La naturaleza del proceso monitorio es la respuesta a estas dos preguntas: 1) ¿es un proceso, procedimiento o estructura?, y 2) si es un proceso, ¿es un proceso de conocimiento (declarativo), ejecutivo o tiene una naturaleza especial?

La doctrina tiende a considerar más que es un procedimiento ${ }^{8}$, que un proceso (la denominación de proceso ha sido generalmente usada es por las normativas de cada país ${ }^{9}$ ), aunque también algunos sostienen que es una estructura. Y quienes lo consideran un procedimiento, a su vez lo excluyen como proceso ejecutivo $^{10}$, para incluirlo como un tipo de proceso de conocimiento. A pesar que puede ser un tema que genere discusión académica, los límites del artículo impiden hacer un estudio de todas las posiciones, y además, lo importante es que funcione en la práctica judicial, sin importar su nombre.

\subsection{Clasificación}

Según Piero Calamandrei ${ }^{11}$, el proceso monitorio puede ser de dos tipos: puro y documental. Es puro si el demandante no tiene la carga de la prueba del hecho, y documental, si por el contrario tiene dicha carga y le incumbe aportar el documento respectivo. Esta clasificación, o al menos sus nombres, ha tenido

6 GARBerí LlobregAt, Jorge. El Proceso Monitorio en la Ley de Enjuiciamiento Civil. Barcelona: Editorial Bosch SA, 2011. p. 105.

AAP Madrid 12. ${ }^{a}$ 25.1.05.

8 CALAMANDREI, Piero. El Procedimiento Monitorio. Op. cit.

9 En Venezuela se llama Procedimiento por Intimación, en Brasil Acción Monitoria y en la mayoría de los demás países Proceso Monitorio.

10 COlmenares URIBE, Carlos Alberto. El Procedimiento Monitorio en América Latina. Pasado, Presente y Futuro. Op. cit., p. 167-169; PÉREZ RAGONE, Álvaro J. (2006). EN TORNO AL PROCEDIMIENTO MONITORIO DESDE EL DERECHO PROCESAL COMPARADO EUROPEO: CARACTERIZACIÓN, ELEMENTOS ESENCIALES Y ACCIDENTALES. Revista de derecho (Valdivia), 19(1), 205-235. Recuperado en 28 de enero de 2014, de http:// www.scielo.cl/scielo.php?script=sci_arttext\&pid=S0718-09502006000100009\&lng=es\&tlng=es. 10.4067/S0718-09502006000100009.

11 CALAMANDREI, Piero. El Procedimiento Monitorio. Op. cit., pp. 26-46. 
crítica como recuerda Carlos Alberto Colmenares Uribe ${ }^{12}$, citando a Dante Barrios de Ángelis, así:

"Por último, hay otro punto de estudio del monitorio que ha presentado bastante controversia frente a la clasificación que se le ha dado de documental y puro, diferenciando los mismos con base en si el acreedor aporta o no una prueba plena que demuestre una obligación en contra del deudor. Según Barrios de Angelis ${ }^{13}$ '...la clasificación clásica en documentales y puros no es adecuada; ya que lo típico de los “documentales” es la plena prueba, documental o no, se les podría designar como de plena prueba, o plenos. En tanto que a los "puros" (que sugieren la idea de lo impuro o lo contaminado como opuesto) bien se los podría clasificar de presuncionales, pues su esencia objetiva radica en la presunción legal ${ }^{14}$ de no oposición' (mayúscula y cursiva del texto)".

\subsection{El proceso monitorio y el debido proceso}

El proceso monitorio no escapa a las discusiones académicas y tal vez la más importante es la que se refiere a la llamada inversión del contradictorio.

Uno de los principios fundamentales del derecho procesal, que contiene su misma esencia, es el debido proceso, y uno de sus elementos es el principio de contradicción, según el cual nadie puede ser vencido sin ser oído, es decir, antes de que el juez dicte la sentencia, las partes, especialmente el demandado, ha debido tener la oportunidad de defenderse de la pretensión.

Sobre la inversión del contradictorio, Joan Picó i Junoy ${ }^{15}$ dice: "Se caracteriza por la inversión del contradictorio, pues éste existe sólo en la medida en que haya oposición del deudor, en cuyo caso, obliga al actor a interponer una demanda", mientras Carlos Alberto Colmenares Uribe ${ }^{16}$ considera que no hay inversión del contradictorio, sino "inversión de la iniciativa de la controversia".

12 NIEVA FENOLL, Jordi et al. El Procedimiento Monitorio en América Latina. Pasado, Presente y Futuro. Op. cit., pp. 122-123.

13 BARRIOS DE ANGELIS, Dante. Op. cit., p. 261.

14 Ya MITTERMAIER, Die summarischen Verfahrensarten, cit., p. 65, señalaba la facilidad presunta en la resolución del conflicto, como carácter del procedimiento sumario; cfr., asimismo, CALAMANDREI, Op. cit., p. 28. Esta nota es de la cita. Las notas 16 y 17 son de la cita.

15 PICÓ I JUNOY, Joan. El Proceso Monitorio. Una Visión española y europea Pensando en Colombia. En: Memorias XXXIII Congreso Colombiano de Derecho Procesal. Cartagena de Indias, 2012. p. 1024.

16 NIEVA FENOLL, Jordi et al. El Procedimiento Monitorio en América Latina. Pasado, Presente y Futuro. Op. cit., p. 127. 
Con el proceso monitorio el principio de contradicción pareciera desconocerse, pues si el demandante inicia el proceso recibiendo la razón del juez, pareciera que nada puede hacer el demandado. Sin embargo, esto no es así, pues el demandado tiene la oportunidad de oponerse a la pretensión, lo cual garantiza el principio de contradicción, y si no lo ejerce será una conducta consciente pasiva de silencio que llevará a la sentencia. Lo que sí hay en el proceso monitorio es una alteración de las etapas del clásico procedimiento ordinario por supresión de algunas, especialmente las de pruebas y alegatos, pero si el demandado se opone, el proceso monitorio termina e inicia el proceso de conocimiento. Más garantía para el demandado, imposible.

Álvaro Pérez Ragone ${ }^{17}$ dice "El derecho de defensa se garantiza brindándole oportunidad para ser oído y oponerse", lo que se hace efectivo con la notificación al demandado, pero una notificación fuera de toda duda, como considera Juan Pablo Correa Delcasso ${ }^{18}$ : "Como afirmáramos en múltiples ocasiones, la notificación del mandato o requerimiento de pago constituye la auténtica columna vertebral del proceso monitorio, en la cual descansa la entera legitimidad de todas las actuaciones posteriores que vayan a realizarse en el mismo". En Colombia, como dice Carlos Alberto Colmenares Uribe ${ }^{19}$, "En este procedimiento está prohibido el emplazamiento y la designación de curador ad litem" y "Los fundamentos para que la notificación del requerimiento de pago no pueda hacerse por aviso o se surta el emplazamiento y se designe curador $a d$ litem estriban en el sencillo pero poderoso argumento que el silencio del deudor conduce necesariamente al nacimiento del título ejecutivo con efecto de cosa juzgada".

\section{EL PROCESO MONITORIO EN IBEROAMÉRICA}

A continuación trataremos de establecer algunos de los aspectos más importantes del proceso monitorio en algunos de los países iberoamericanos (Uruguay, España y Colombia) que lo han adoptado, siguiendo como criterio

17 PÉREZ RAGONE, Álvaro J. “En torno al procedimiento monitorio desde el derecho procesal comparado europeo: caracterización, elementos esenciales y accidentales”. Revista de derecho (Valdivia), 19 (1), 2006, pp. 205-235. Recuperado en 28 de enero de 2014, de [http://www. scielo.cl/scielo.php?script=sci_arttext\&pid=S0718-09502006000100009\&lng=es\&tlng=es. 10.4067/S0718-09502006000100009].

18 CORREA DELCASSO, Juan pablo. "Comentarios a la Propuesta de Reglamento por el que se Establece Un Proceso Monitorio Europeo”. En: Revista Iberoamericana de Derecho Procesal, año $\mathrm{V}$, núm. 7, 2005. p. 53.

19 NIEVA FENOLL, Jordi et al. El Procedimiento Monitorio en América Latina. Pasado, Presente y Futuro. Op. cit., pp. 148-149. 
identificar algunos de los temas que denominamos nociones generales en este estudio, es decir, trataremos de establecer su fin (si solo es crear un título ejecutivo o sirve para otros casos), naturaleza (si se considera un proceso de conocimiento, ejecutivo o especial) y clasificación (si es de plena prueba o presuncional, y documental o puro, en las terminologías de Barrios de Ángelis y Calamandrei, respectivamente).

Hemos estudiado en este artículo el proceso monitorio de Uruguay y España, el primero por ser el pionero y más amplio, y el segundo por ser el más exitoso en la actualidad, respectivamente, lo que nos permite observar dos cosas: primera, que el proceso monitorio puede servir para algo más que crear un título ejecutivo; y segunda, que es el proceso, tal vez, que más garantiza la tutela judicial efectiva y se ajusta a los principios constitucionales de garantías mínimas judiciales.

\subsection{Cuadro comparativo}

El proceso monitorio ha sido adoptado en Uruguay, Venezuela, Brasil, Argentina (Provincia de La Pampa), España, Perú, Chile, Honduras, Costa Rica, El Salvador y Colombia. En el siguiente cuadro se resumen algunos de los principales aspectos del proceso monitorio en estos países, como la fecha de adopción, fin, naturaleza y clasificación o tipo, código o ley y artículos que lo regulan.

\section{El proceso monitorio en iberoamerica}

\begin{tabular}{|l|l|l|l|l|l|l|}
\hline \multicolumn{1}{|c|}{ Pais } & Año & \multicolumn{1}{c|}{ Fin } & Naturaleza & \multicolumn{1}{c|}{ Tipo } & \multicolumn{1}{c|}{ Código/Ley } & \multicolumn{1}{c|}{ Artículos } \\
\hline Uruguay & 1998 & General & Declarativo & Documental & Código General del Proceso & $351-370$ \\
\hline Venezuela* $^{*}$ & 1990 & Especial & Ejecutivo & Documental & Código de procedimiento Civil & $640-652$ \\
\hline Brasil $^{* *}$ & 1995 & Especial & Especial & Documental & Código de Proceso Civil & 1102 A-B-C \\
\hline Argentina $^{* * *}$ & 1999 & General & Especial & Documental & Código Procesal Civil y Com... & $463-470$ \\
\hline España $^{2} 2000$ & Especial & Declarativo & Documental & Ley de Enjuiciamiento Civil & $812-818$ \\
\hline Perú & 2005 & Filiación & Declarativo & Puro & Ley 28.457 del 7 de enero de 2005 & $1-5$ \\
\hline Chile***:** & 2006 & Laboral & Declarativo & Puro & Ley 20.087 del 3 de enero de 2006 & $496-502$ \\
\hline Honduras & 2006 & Especial & Declarativo & Documental & Código Procesal Civil & $676-685$ \\
\hline Costa Rica & 2007 & Especial & Declarativo & Documental & Ley 8624 del 1 de Noviembre de 2007 & $1-7$ \\
\hline El Salvador & 2008 & Especial & Especial & Documental & Código Procesal Civil y Com.. & $489-500$ \\
\hline Colombia & 2012 & Especial & Declarativo & Puro & Código General del Proceso & $419-421$ \\
\hline
\end{tabular}

Fin General: sirve para crear título ejecutivo y otros casos/ Especial: sirve solo para crear título ejecutivo.

Tipo: Documental o de plena prueba / Puro o presuncional.

*Se llama Procedimiento por Intimación

*: Se llama Acción Monitoria

**:* Solo en la Provincia de la Pampa.

*****:Proceso Monitorio de la Familia (filiación judicial de paternidad extramatrimonial)

*****:Proceso Monitorio Laboral. Los art. 496-502 son del Código de Trabajo. 


\subsection{Código Procesal Civil modelo para Iberoamérica}

El Código Procesal Civil Modelo para Iberoamérica de 1988 adoptado por el Instituto Iberoamericano de Derecho Procesal estableció el que denominó proceso de estructura monitoria, dentro de la clasificación de los procesos de conocimiento, junto al ordinario, en los arts. 311 a 316.

Previamente a ver el fin, naturaleza y clasificación del proceso monitorio en el Código, es necesario recordar su Exposición de Motivos:

"El proceso monitorio adoptado inclusive para el juicio ejecutivo en el Anteproyecto de Código Modelo para Iberoamérica sí constituye una novedad y resulta polémico, por lo cual nos permitiremos hacer una breve referencia al mismo.

Este proceso o, más precisamente, la estructura monitoria, se propone no sólo para la ejecución de los títulos extrajudiciales (títulos ejecutivos) sino también para los judiciales (sentencias). Y no sólo para este juicio, sino para varios otros que pueden adoptar, con ventajas, esa estructura, tales como el desalojo (desahucio), entrega de la cosa, entrega de la herencia, escrituración judicial (derivada de promesa de compraventa, por ejemplo, etc.).

Resulta, como sabemos, discutible, el origen de este proceso, aun cuando parece iniciarse en la Italia Comunal del Siglo XIII, ${ }^{20}$ con perfiles determinados y con el fin fundamental de acelerar el cobro de determinados documentos. ${ }^{21}$ El régimen se desarrolla en los países europeos ${ }^{22}$ y también

20 Más ampliamente: CALAMANDREI, P. El procedimiento monitorio. EJEA Buenos Aires, 1953. GUTIERREZ ALVIZ, F. y CONRADI. EL procedimiento monitorio: Estudio de Derecho comparado. Sevilla, 1972. esp. p. 16 y ss. FAIREN GUILLEN. Y., El juicio ordinario y los plenarios rápidos. Barcelona, '1953, . esp. pp. 42 y ss TOMAS y VALIENTE F., "Estudio histórico jurídico del proceso monitorio", En: Revista Iber. de Derecho Procesal, 1966, p. 50. VESCOV1 E., TORELLO, L., y VIERA, L. A. "La reforma del proceso ejecutivo para Iberoamérica: la adopción del procedimiento de estructura monitoria” en Revista Uruguaya de Derecho Procesal, 1978, p. 462.

${ }^{21}$ Entre tales procedimientos se destacan el denominado inicialmente praeceptum o mandatum de solvendo con cláusula justificativa que luego se denominaría monitorio. El procedimiento se inicia con una orden del juez para pagar o hacer alguna cosa, emanada sin previa cognición (o cognición muy sumaria) lo cual se justifica con la cláusula del documento. En virtud ella caben dos posibilidades: el intimado no comparece y entonces el mandato queda confirmado, pasa en cosa juzgada,, o el deudor se presenta y por ese sólo hecho deben seguirse las ritualidades del juicio ordinario. En todo caso hay una diferencia entre los procesos sumarios comunes (plenarios rápidos) y estos especiales, si es que deben merecer la categorización (de sumarios).

22 En Alemania se señala el procedimiento monitorio (mahnverfah ren) y el documental (urkunderverfahren) regulados el primero en los artículos 688-703 de la Z.P.O. alemana y el segundo en los artículos 502-600; en Italia existe el procedimiento de iniuzione (injucción) (artículos 
en alguno de Latinoamérica como sucede en Uruguay. ${ }^{23}$ Lo hemos propiciado como solución para el Derecho latinoamericano, tanto para algún país en particular ${ }^{24}$ como para el Anteproyecto de Código Modelo para Iberoamérica. ${ }^{25}$

Este procedimiento propuesto -inclusive para la formación de ciertos títulos ejecutivos ${ }^{26}$ - consiste en que presentado el documento o los elementos constitutivos y que demuestran la fundabilidad de la pretensión ${ }^{27}$, el Juez

633 a 656 del. CPC). En Austria se tiende a una solución similar, en la última reforma, permitiendo que, en caso de rebeldía, se dicte una sentencia sobre el fondo.

23 En Uruguay, desde la aprobación del Código de Procedimiento Civil (1877) se incluyen en esta categoría el juicio de entrega de la cosa (de dar cosa cierta y determinada, derivada de un contrato en el cual el actor demuestre haber cumplido por su parte, como puede ser la compraventa); la entrega efectiva de la herencia (a la que obste alguna persona frente al heredero declarado).

Posteriormente, en 1927, la 'ley de desalojos admitió este juicio para el desalojo, previendo la posibilidad de intimar el desalojo y citar de excepciones tanto al vencimiento del contrato como en el caso de mal pagador, intimado el pago.

En 1965 se incluyó para el juicio ejecutivo. También la jurisprudencia entiende que corresponde para la resolución de la promesa de compraventa de inmuebles (verificado también el incumplimiento) (ley de 1837 número 9.706) y la ley 14.219 para rebaja del alquiler (también probados documentalmente los supuestos del ingreso del arrendatario).

Más ampliamente:, ARLAS J., "El proceso monitorio en el Derecho uruguayo" en Rey. D.J.A., t. 5\& p. 63. VESCOVI, Enrique, "El proceso monitono", en Revista de Derecho Procesal (mexicana), Año 4, números 4 a 6, p. 89). TEiTELBAUM, J., "El proceso monitorio uruguayo", en Revista Uruguaya de Derecho Procesal, 1977, p. 27.

24 En el trabajo sobre "Conveniencia de reformar el sistema argentino en materia del juicio ejecutivo presentado a]. XII Congreso Nacional Argentino de Derecho Procesal” (Rosario de Santa Fe, mayo de 1983) lo pro poníamos, junto con los profesores. Torello y Viera,, como solución para el proceso ejecutivo en la República Argentina.

25 Así, en el libro de Homenaje a Jaime Guasp (Madrid, 1984) en el trabajo que escribimos sobre: "La reforma del proceso ejecutivo para Iberoamérica: la adopción del proceso de estructura monitoria".

26 Así se ha sostenido en el Derecho uruguayo que el proceso ejecutivo es de conocimiento y no de ejecución por parte de la doctrina que no compartimos y, en ese caso, se concluye en que el monitorio también lo sería de conocimiento ya que el título ejecutivo no preexiste al proceso, si no que se forma dentro del mismo (Al menos luego de cumplida la intimación de pago, requisito previo en el Derecho uruguayo) (TEITELBAUM, J. "Adopción de procesos monitorios para obtener otros títulos ejecutivos”. Ponencia al XIII Congreso Nacional Argentino de Derecho Procesal y IV Encuentro Panamericano (Mar del Plata, octubre de 1985).

27 En el monitorio documental, como lo sería el juicio ejecutivo en Uruguay, mediante la presentación del título, el juez verifica el (o los) documentos; más compleja es la situación en el no documental (en el que algunos sostienen que se forma el título dentro del monitorio), pero es preferible verificar, igualmente, la exigencia de ciertos supuestos que permiten al tribunal, mediante una cognitio sumaria, dictar su sentencia y luego citar de excepciones. 
verifica los presupuestos generales (capacidad, legitimación, competencia, etc.) y los especiales (en el juicio ejecutivo la existencia del título, en la entrega de la cosa que surge de un contrato, en el cual el actor demuestra haber cumplido, por ej. en el desalojo, el vencimiento del plazo, la falta de pago, etc.) y acoge la demanda mediante una sentencia (cuya naturaleza no interesa dilucidar aquí)" ${ }^{28}$

La misma sentencia dispone un emplazamiento (o citación de excepciones al demandado) para comparecer y oponerse a la demanda. En caso de que no lo haga en el término perentorio establecido, la sentencia pasa en autoridad de cosa juzgada y el juicio queda terminado:

La experiencia, al menos la uruguaya, demuestra que si el Juez cumple normalmente su función verificadora, ${ }^{29}$ en un $80 \%$ de los juicios no se oponen excepciones, lo que significa que el proceso termina con un escrito y una providencia judicial.

28 Así en nuestro Derecho se discute si la sentencia inicial es definitiva o interlocutoria. Lo esencial es que, en todo caso, el actor podrá impugnar la resolución judicial mediante los recursos (especialmente el de apelación) mientras que para el demandado la única forma de impugnación. es a través de las excepciones. Pongamos el ejemplo de la norma que rige el juicio ejecutivo en Uruguay y que dispone:

Ley número 13.355 artículo 53; "Cuando se pida la ejecución en virtud de alguno de los títulos que la aparejan,, el juez decretará inmediatamente el embargo y mandará llevar adelante la ejecución hasta hacerse efectiva. la cantidad reclamada, los intereses, costas y costos. Si no considerase bastante el documento declarará que no hay lugar a la ejecución. Una y otra cosa sin noticia del deudor. En el mismo auto que decrete el embargo citará de excepciones al ejecutado. Si se opusieren excepciones se procederá de conformidad con lo dispuesto por los artículos 889. y Ss. C.P.C.” (Es decir traslado al ejecutante, apertura a prueba, si corresponde y sentencia apelable).

En las estadísticas obtenidas en algunos años los casos en que no se opusieron excepciones alcanzaron al $80 \%$.

29 Es elemental que se parte de la base de que el tribunal cumple su función y que es el propio juez - no el Secretario- que provee esta de manda que conduce a una sentencia inmediata. Y que, naturalmente quien verifique los presupuestos. Entre otros el de la debida citación y emplaza miento del demandado. Lo que, por otra parte, es lo que debe hacer en to dos los casos. Al efecto establece el nuevo régimen mexicano del C.P'.C.D.F.:

Artículo 47: "El juez examinará de oficio la legitimación procesal de las partes Artículo 271, "Para hacer la declaración de rebeldía, el juez examinará escrupulosamente y bajo su más estricta responsabilidad si las citaciones y notificaciones precedentes están hechas al demandado en la forma legal... Si el juez encontrare que el emplazamiento no se hizo correcta mente mandará reponerlo...

Verificados correctamente los presupuestos de los cuales emana una fuerte presunción de la razón del demandante nada impide que se diete una sentencia de acogimiento condicionada (a que el demandado no deduzca sus defensas o excepciones). Las notas 23 a 32 son de la cita. 
Por el contrario si el demandado comparece y opone excepciones (defensas) se confiere traslado de ellas al actor, se abre a prueba y se siguen las ritualidades del juicio ordinario, u ordinario abreviado. Es decir que se invierte la regla del contradictorio, el cual aparece como eventual, condicionado a la comparecencia del demandado y a la oposición de sus excepciones que, según los juicios, pueden aparecer como limitadas por la ley en atención a la presunción de autenticidad que, normalmente, emana de los documentos (en el monitorio documental).

Es decir que se diseña un tipo de proceso sumamente abreviado, sin desconocer las esenciales garantías de la defensa en juicio.

También es necesario recordar las Propuestas para las Bases del Nuevo Código Modelo de Proceso Civil para Iberoamérica ${ }^{30}$ elaboradas por una comisión ${ }^{31}$ del Instituto Iberoamericano de Derecho Procesal, en la que se sugiere "AMPLIAR EL PROCESO MONITORIO PARA QUE ADMITA PRUEBA TESTIMONIAL PRODUCIDA EN AUDIENCIA PROPIA (ART. 312.1)" (mayúscula y negrita del texto).

2.2.1 Fin: sirve para crear un título ejecutivo, pero también para otros casos, como establece el art. 311, así: "El proceso de estructura monitoria se aplicará en los casos especialmente previstos por la ley y además en los siguientes procesos: 1) ejecutivos; 2) desahucio o desalojos; 3 ) entrega de la cosa; 4) entrega efectiva de la herencia; 5) resolución por falta de pago o escrituración judicial de promesas inscriptas en los respectivos registros (compra-venta de inmueble o de establecimiento o de empresa comercial o de unidad en propiedad horizontal)".

2.2.2 Naturaleza: el Código lo denomina proceso de estructura monitoria y lo clasifica como una especie de proceso de conocimiento, junto al ordinario, es decir, no lo considera ni de ejecución ni especial.

2.2.3 Clasificación: es de plena prueba o documental, según el art. 312.1, así: “En todos los casos se requerirá documento auténtico o autenticado judicialmente en la etapa preliminar respectiva", aunque tiene una excepción: "Exceptuase el caso de entrega de la cosa, derivada de contrato del que resulte la obligación de dar, si se trata de contrato que no requiere documentación. En este caso

30 Disponible en la página Web del Instituto Iberoamericano de Derecho Procesal http://iibdp. org/index.php/es/banco-de-documentos.html

31 Formada por Ada Pellegrini Grinover, Alberto Said, Alejandro Abal Oliú, Joan Picó i Junoy, Jorge W. Peyrano, José Pedro Silva, Luis María Simón, Nelson Ramírez Jiménez y Ulises Canosa Suárez. 
y en etapa preliminar, que se seguirá por la vía incidental, podrá establecerse la prueba de la existencia del contrato y su cumplimiento por parte del actor" (art. 312.2). Aunque consideramos que no por no exigirse documento deje de ser documental y sea puro, en la terminología de Piero Calamandrei, sino sigue siendo de plena prueba, como lo denomina Barrios de Ángelis ${ }^{32}$.

\subsection{Uruguay}

El Código General del Proceso de Uruguay de 1988 reguló el proceso monitorio siguiendo el Código Procesal Civil Modelo para Iberoamérica, ambos trabajos con el aporte de Enrique Véscovi.

2.3.1 Fin: siguiendo el criterio del Código Procesal Civil Modelo para Iberoamérica, en Uruguay el proceso monitorio sirve para crear un título ejecutivo, pero también para estos otros casos: 1) entrega de la cosa (art. 364), 2) entrega efectiva de la herencia (art. 365), 3) pacto comisorio (art. 366), 4) escriturización forzada (art. 367), 5) resolución de contrato de promesa (art. 368), 6) separación de cuerpos y divorcio (art. 369), y 7) cesación de condominio de origen contractual (art. 370).

2.3.2 Naturaleza: de igual manera que el Código Procesal Civil Modelo para Iberoamérica, en Uruguay se denomina proceso de estructura monitoria y se clasifica como una especie de proceso de conocimiento, junto al ordinario, es decir, no se considera ni de ejecución ni especial.

2.3.3 Clasificación: igual que el Código Procesal Civil Modelo para Iberoamérica, en Uruguay, es de plena prueba o documental, según el art. 352.1, así: "En todos los casos, para promover la demanda, se requerirá documento auténtico o autenticado notarial o judicialmente en la etapa preliminar respectiva”, y también tiene una excepción: "Exceptúase el caso previsto en el artículo 364, cuando se trate de contrato que pueda ser probado por testigos. En este caso y en etapa preliminar que se seguirá pro vía incidental, podrá establecerse la prueba de la existencia del contrato y de su cumplimiento por el actor" (art. 352.2).

\subsection{España}

Según Joan Picó i Junoy 33 "La novedad más exitosa de la Ley de Enjuciaimiento (sic) Civil (LEC) española de 2000 fue, sin ningún género de dudas, el proceso monitorio. Y la reforma de la LEC efectuada mediante la ley 37/2011, de 10 de

32 Citado por COLMENARES URIBE, Carlos Alberto. El Procedimiento Monitorio en América Latina. Pasado, Presente y Futuro. Op. cit., pp. 122-123.

33 PICÓ I JUNOY, Joan. El Proceso Monitorio... Op. cit., p. 1021. 
octubre, ha venido a consolidarlo y darle el máximo ámbito de aplicación como mecanismo judicial para la rápida la tutela del crédito, al no limitarlo a cuantía dineraria alguna. El proceso monitorio en España es el tipo de juicio civil más utilizado ante los tribunales y el más eficaz, como lo acreditan las estadísticas ${ }^{34}$. Ééstas (sic) nos demuestran el continuo crecimiento en su uso: de los 420.599 procesos monitorios de 2007 se pasó a 895.875 en 2010, esto es, en cuatro años se ha duplicado el número de estos procesos ${ }^{35}$; siendo muy previsible que esta cifra siga aumentando dado que la reforma procesal de 2011 ha eliminado todo límite cuantitativo de acceso al mismo. Y, de igual modo, las estadísticas nos acreditan su alto nivel de eficacia: así, en 2010, el 43,5 \% de los procesos monitorios acabaron logrando la finalidad perseguida, esto es, el pago ${ }^{36}$ o la ejecución ${ }^{37 ”}$.

El título del anterior texto es: “1. INTRODUCCIÓN: EL ROTUNDO ÉXITO DEL PROCESO MONITORIO EN ESPAÑA Y EUROPA. Y ¿POR QUÉ NO EXISTE EN COLOMBIA?" (Mayúscula y negrita del texto). Esta pregunta sirve para hacerla a los países que aún no han adoptado el proceso monitorio, no por moda, sino como garantía de la tutela judicial efectiva.

2.4.1 Medidas cautelares. Jurisprudencia española: Jorge Garberí Llobregat ${ }^{38}$ cita esta jurisprudencia"39: "PRIMERO.- Ciertamente que la cuestión que se plantea en el presente recurso de apelación es novedosa y, además, no ha sido objeto de tratamiento claro ni mayoritario por la doctrina. Es un tema obviado generalmente por los comentaristas de la nueva ley. La juez a quo niega la posibilidad de adoptar medidas cautelares en los procesos monitorios, en atención a la naturaleza jurídica de estos...

CUARTO.- Un tercer argumento vendría dado por la finalidad de toda medida cautelar: «asegurar la efectividad de la tutela judicial que pudiera otorgarse en la sentencia estimatoria que se dictase» (art. 724 LEC). Tampoco se comprende bien por qué esa garantía sólo se podría pedir cuando el proceso monitorio se convirtiera en juicio declarativo plenario, ordinario o verbal. El

34 Datos extraídos de la Memoria del Consejo General del Poder Judicial aprobada por el Pleno el 21 de mayo de 2011 (cfr. http://www.poderjudicial.es/cgpj/es/Poder_Judicial; fecha de la consulta: el 29 de mayo de 2011).

35 Cfr. La Justicia dato a dato. Año 2010, en www.poderjudicial.es (Memoria del CGPJ en pdf. p. 61).

36 En un $7,7 \%$.

37 En un 35,8\%. Las notas 37 a 40 son de la cita.

38 GARBERÍ LLOBREGAT, Jorge. Op. cit., p. 303.

39 AAP Zaragoza 5. ${ }^{\text {a }}$ 8.11.02. 
plazo de 20 días que el requerido tiene para oponerse es suficiente para hacer inefectiva la sentencia definitiva”. En Colombia, según el parágrafo del art. 421 del Código General del Proceso, "Podrán practicarse las medidas cautelares previstas para los demás procesos declarativos. Dictada la sentencia a favor del acreedor, proceden las medidas cautelares propias de los procesos ejecutivos".

2.4.2 Fin: según el art. 812 de la Ley de Enjuiciamiento Civil de 2000, el proceso monitorio sirve para la creación de un título judicial. La norma establece: "Podrá acudir al proceso monitorio quien pretenda de otro el pago de deuda dineraria de cualquier importe, líquida, determinada, vencida y exigible...".

2.4.3 Naturaleza: la Ley de Enjuiciamiento Civil lo denomina proceso monitorio y lo clasifica como una especie de proceso de conocimiento.

2.4.4 Clasificación: es de plena prueba o documental, según el art. 812, así: "1. Podrá acudir al proceso monitorio quien pretenda de otro el pago de deuda dineraria de cualquier importe, líquida, determinada, vencida y exigible, cuando la deuda se acredite de alguna de las formas siguientes:

1. ${ }^{\mathrm{a}}$ Mediante documentos, cualquiera que sea su forma y clase o el soporte físico en que se encuentren, que aparezcan firmados por el deudor o con su sello, impronta o marca o con cualquier otra señal, física o electrónica.

2. ${ }^{\text {a }}$ Mediante facturas, albaranes de entrega, certificaciones, telegramas, telefax o cualesquiera otros documentos que, aun unilateralmente creados por el acreedor, sean de los que habitualmente documentan los créditos y deudas en relaciones de la clase que aparezca existente entre acreedor y deudor".

\subsection{Colombia}

El Código General del Proceso (ley 1564 del 12 de julio de 2012, arts. 419 a 421) consagró de manera expresa por primera vez en Colombia el proceso monitorio, aunque como considera Carlos Alberto Colmenares Uribe ${ }^{40}$ desde hace muchos años existen procesos de estructura monitoria.

2.5.1 Fin: es la creación de un título ejecutivo, como establece el art. 419: "Quien pretenda el pago de una obligación en dinero, de naturaleza contractual, determinada y exigible que sea de mínima cuantía, podrá promover proceso monitorio...". En Colombia, contrario a Uruguay, el proceso monitorio no tiene como fin otros casos diferentes a la creación de un título ejecutivo.

40 COLMENARES URIBE, Carlos Alberto. El Proceso Monitorio en el Código General ... Op. cit., pp. 1152-1154. 
2.5.2 Naturaleza: está regulado dentro de los procesos de conocimiento (llamados declarativos por el Código).

2.5.3 Clasificación: es presuncional como lo llamaría Barrios de Ángelis o puro según Calamandrei, en lo que también se diferencia del proceso monitorio uruguayo.

\section{El proceso monitorio. Tendencia del dereCho PROCESAL IBEROAMERICANO}

La implementación del proceso monitorio en Uruguay, Venezuela, Brasil, Argentina (Provincia de La Pampa), España, Perú, Chile, Honduras, Costa Rica, El Salvador y Colombia nos permite concluir que es una nueva tendencia del derecho procesal iberoamericano que se ha impuesto por la sólida fundamentación teórica que lo justifica y especialmente por la necesidad de una tutela judicial efectiva dentro de un plazo razonable. Muy a pesar de las resistencias y críticas que se le hagan, es una tendencia que no tiene marcha atrás y que merece toda la atención para ir puliendo esos detalles que lo requieren e ir ajustando las normativas nacionales para lograr ese caro objetivo que es la tutela judicial efectiva dentro de un plazo razonable.

Los redactores del Código Procesal Civil Modelo para Iberoamérica lo afirmaron: "El proceso monitorio adoptado inclusive para el juicio ejecutivo en el Anteproyecto de Código Modelo para Iberoamérica sí constituye una novedad y resulta polémico...".

De los diez países suramericanos, siete han adoptado el proceso monitorio (Uruguay, Venezuela, Brasil, Argentina, Perú, Chile y Colombia, en orden cronológico) solo faltando Bolivia, Ecuador y Paraguay; y de los siete países centroamericanos, tres lo han implementado (Honduras, Costa Rica y El Salvador, en orden cronológico) faltando Belice, Guatemala, Nicaragua y Panamá. Y sumando a España, para un total de doce países iberoamericanos que han adoptado el proceso monitorio.

\section{CONCLuSiones}

1. El proceso monitorio es una de las nuevas tendencias del derecho procesal iberoamericano.

2. El proceso monitorio, como cualquier estudio del derecho procesal y del conocimiento humano, no está exento de aspectos controversiales y críticas, 
como su fin, naturaleza, clasificación, y especialmente la llamada inversión del contradictorio, etc. Sin embargo, dichas polémicas no pueden impedir su implementación en beneficio de la tutela judicial efectiva.

3. Además de su fin principal de garantizar la tutela judicial efectiva, el proceso monitorio cumple otro fin indirecto muy importante: reduce la cantidad de procedimientos ordinarios o verbales, según cada país, lo que lleva a una descongestión natural sin sacrificar el acceso a la tutela judicial efectiva.

4. Si hay una institución del derecho procesal que acerque más al ciudadano a la administración de justicia y logre la tutela judicial efectiva, es el proceso monitorio. Esta esperanza del ciudadano en la justicia es suficiente para continuar su implementación en toda Iberoamérica, con las particularidades de cada Estado, a pesar de las críticas, que finalmente deben servir para mejorar su funcionamiento, pues como dijo Franz Klein ${ }^{41}$ sobre las nuevas ideas: "... en un primer momento resultan extrañas y en raro contraste con las costumbres, y originan la crítica más violenta. Una vez puestas en práctica y perfeccionadas, de pronto se tornan transparentes e indispensables y nadie entiende ya cómo las cosas pudieron alguna vez funcionar de otra manera".

Finalmente, como dijo José Luis Vázquez Sotelo ${ }^{42}$ sobre el proceso civil en el siglo XXI, "...el proceso civil se encuentra ante nuevos retos a los que ha de hacer frente. Se trata de intuir y en lo posible de adivinar cuales serán las orientaciones del futuro proceso civil". Ante esto, qué mejor que guardar la esperanza en el proceso monitorio, ya que el clásico procedimiento ordinario no fue del todo eficaz.

\section{REFERENCIAS}

BARRIOS DE ANGELIS, Dante. Teoría del Proceso. $2^{\text {a }}$ ed., Buenos Aires: Editorial B de F, 2002.

CALAMANDREI, Piero. El Procedimiento Monitorio. Buenos Aires: Librería El Foro, 2006.

CHIOVENDA, Giuseppe. Principios de Derecho Procesal Civil. Tomo I. Traducción española de la $3^{\text {a }}$ ed. italiana. Prólogo y notas del profesor José Casáis y Santoló, Madrid: Editorial Reus SA, 1922.

41 Citado por CAPPELLETTI, Mauro. El Testimonio de la Parte en el Sistema de la Oralidad. Tomo I. La Plata: Librería Editora Platense, 2002.

42 VÁZQUEZ SOTELO, José Luis. “El Proceso Civil y su Futuro”. En: Revista Iberoamericana de Derecho Procesal, año II, núm. 3, 2003. p. 69. 
Código Procesal Civil Modelo para Iberoamérica de 1988 del Instituto Iberoamericano de Derecho Procesal y Propuestas para las Bases del Nuevo Código Modelo de Proceso Civil para Iberoamérica de 2012 del Instituto Iberoamericano de Derecho Procesal.

COLMENARES URIBE, Carlos Alberto et al. El Procedimiento Monitorio en América Latina. Pasado, Presente y Futuro. Bogotá DC: Editorial Temis SA, 2013.

, El Proceso Monitorio en el Código General del Proceso. En: Memorias XXXIII Congreso Colombiano de Derecho Procesal. Cartagena de Indias, 2012. Memorias.

, Estructura Monitoria y la Hipoteca. En: Memorias XXXI Congreso Colombiano de Derecho Procesal. Cartagena de Indias, 2010.

CÓDIGO GENERAL DEL PROCESO. Colombia. Ley 1564 de 2012.

CORREA DELCASSO, Juan Pablo. El Proceso Monitorio. Barcelona: José María Bosch, 1998.

, El Proceso Monitorio Europeo. Madrid: Marcial Pons Ediciones Jurídicas y Sociales SA, 2008.

, Comentarios a la Propuesta de Reglamento por el que se Establece Un Proceso Monitorio Europeo. En: Revista Iberoamericana de Derecho Procesal, año $\mathrm{V}$, núm. 7, 2005.

DEVIS ECHANDÍA, Hernando. Teoría General del Proceso. $3^{\text {a }}$ ed., Buenos Aires: Editorial Universidad, 2004.

GARBERÍ LlOBREGAT, Jorge. El Proceso Monitorio en la Ley de Enjuiciamiento Civil. Barcelona: Editorial Bosch SA, 2011.

GARCÍA CANO, Sandra. Estudio sobre el Proceso Monitorio Europeo. Editorial Thomson, Aranzadi, 2008.

GARCÍA GIL, Francisco Javier. Práctica del Proceso Monitorio. Legislación, Comentarios, Jurisprudencia y Formularios. Editorial La ley SAU, 2010.

GÓMEZ AMIGO, Luis. El Proceso Monitorio Europeo. Editorial Thomson Aranzadi, 2008.

LÓPEZ BLANCO, Hernán Fabio. Instituciones de Derecho Procesal Civil Colombiano. Tomo I. Parte General. 10ª ed., Bogotá DC: Dupré Editores, 2009.

LORCA NAVARRETE, Antonio María. El Proceso Monitorio Regulado en la Ley de Enjuiciamiento Civil. Madrid: Dykinson, 2000. 
MAGRO SERVET, Vicente. El Proceso Monitorio. Sepín Editorial Jurídica.

MARINONI, Luiz Guilherme; PÉREZ RAGONE, Álvaro; NÚÑEZ OJEDA, Raúl. Fundamentos del Proceso Civil. Hacia una Teoría de la Adjudicación. Santiago: Abeledo Perrot, 2010.

MARTÍNEZ DE BELTRÁN DE HEREDIA, Francisco. El Proceso Monitorio. Teoría y Práctica. Madrid: Difusión Jurídica y Temas de Actualidad S.A., 2007.

MARTÍN JIMÉNEZ, Carlos Manuel. El Proceso Monitorio al Alcance de todos. Guía Práctica. Editorial Lex Nova SAU, 2012.

MORAHAN, Mariano. El Procedimiento Monitorio. Paraná: Delta Editora SRL, 2011.

NIEVA FENOLL, Jordi. Aproximación al Origen del Procedimiento Monitorio. En: El Procedimiento Monitorio en América Latina. Pasado, Presente y Futuro. Bogotá DC: Editorial Temis SA, 2013.

QUÍleZ MORENO, José María. El Proceso Monitorio: Estudio Doctrinal, Jurisprudencial y Futura Realidad de la e-justicia. Madrid: 2011.

PARRA QUIJANO, Jairo. Prólogo a El Procedimiento Monitorio en América Latina. Pasado, Presente y Futuro. Bogotá DC: Editorial Temis SA, 2013.

PELLEGRINI GRINOVER, Ada. "Procedimientos Preliminares o Sumarios: Alcance e Importancia”. En: Revista Iberoamericana de Derecho Procesal, Año III, No 4, Instituto Iberoamericano de Derecho Procesal, 2004.

PÉREZ RAGONE, Álvaro J. "En torno al procedimiento monitorio desde el derecho procesal comparado europeo: caracterización, elementos esenciales y accidentales". Revista de derecho (Valdivia), 19 (1), 2006, pp. 205-235. Recuperado en 28 de enero de 2014, de [http://www.scielo.cl/scielo.php?script $=$ sci_arttext\&pid=S0718-09502006000100009\&lng=es\&tlng=es.10.4067/ S0718-09502006000100009].

PICÓ I JUNOY, Joan. El Proceso Monitorio. Una Visión española y europea Pensando en Colombia. En: Memorias XXXIII Congreso Colombiano de Derecho Procesal. Cartagena de Indias, 2012.

POVEDA PERDOMO, Abelardo. Manual del Proceso Monitorio. El Modelo Documental Español. $1^{\mathrm{a}}$ ed., Bogotá DC: Librería Ediciones del Profesional Ltda., 2006.

QUINTERO, Beatriz; PRIETO, Eugenio. Teoría General del Derecho Procesal. 4ª ed., Bogotá DC: Editorial Temis SA, 2008.

VÁZQUEZ SOTELO, José Luis. "El Proceso Civil y su Futuro”. En: Revista Iberoamericana de Derecho Procesal, año II, núm. 3, 2003. 